Boise State University

ScholarWorks

Biology Faculty Publications and Presentations

Department of Biological Sciences

$11-1-2010$

\title{
Non-Native Salmonids Affect Amphibian Occupancy at Multiple Spatial Scales
}

David S. Pilliod

Forest and Rangeland Ecosystem Science Center

Blake R. Hossack

Northern Rocky Mountain Science Center

Peter F. Bahls

Northwest Watershed Institute

Evelyn L. Bull

USDA Forest Service Pacific Northwest Research Station

Paul Stephen Corn

Northern Rocky Mountain Science Center

See next page for additional authors 


\section{Authors}

David S. Pilliod, Blake R. Hossack, Peter F. Bahls, Evelyn L. Bull, Paul Stephen Corn, Grant Hokit, Bryce A. Maxell, James C. Munger, and Aimee Wyrick 


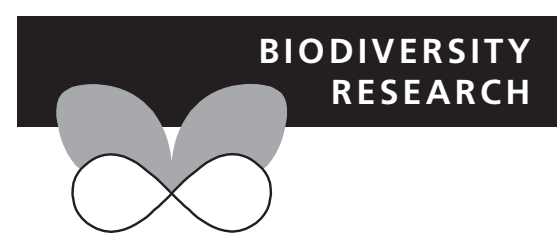

\title{
Non-native salmonids affect amphibian occupancy at multiple spatial scales
}

\author{
David S. Pilliod ${ }^{1 \star}$, Blake R. Hossack ${ }^{2}$, Peter F. Bahls ${ }^{3}$, Evelyn L. Bull ${ }^{4}$, \\ Paul Stephen Corn ${ }^{2}$, Grant Hokit ${ }^{5}$, Bryce A. Maxell ${ }^{6}$, James C. Munger ${ }^{7}$ \\ and Aimee Wyrick ${ }^{8}$
}

${ }^{1}$ US Geological Survey, Forest and Rangeland Ecosystem Science Center, Snake River Field Station, 970 Lusk St., Boise, ID 83706, USA, ${ }^{2}$ US Geological Survey, Northern Rocky Mountain Science Center, Aldo Leopold Wilderness Research Institute, 790 E. Beckwith Ave., Missoula, MT 59801, USA, ${ }^{3}$ Northwest Watershed Institute, 3407 Eddy Street, Port Townsend, WA 98368, USA, ${ }^{4}$ USDA Forest Service Pacific Northwest Research Station, 1401 Gekeler Lane, La Grande, OR 97850 USA, ${ }^{5}$ Department of Biology, Carroll College, 1601 North Benton Ave., Helena, MT 59625, USA, ${ }^{6}$ Montana Natural Heritage Program, 1515 East Sixth Avenue, Helena, MT 596201800, USA, ${ }^{7}$ Department of Biological Sciences, Boise State University, Boise, ID 83725, USA, ${ }^{8}$ Biology Department, Pacific Union College, One Angwin Avenue, Angwin, CA 94508, USA

${ }^{*}$ Correspondence: David S. Pilliod, US Geological Survey, Forest and Rangeland Ecosystem Science Center, Snake River Field Station, 970 Lusk St., Boise, ID 83706, USA. E-mail: dpilliod@usgs.gov

\section{ABSTRACT}

Aim The introduction of non-native species into aquatic environments has been linked with local extinctions and altered distributions of native species. We investigated the effect of non-native salmonids on the occupancy of two native amphibians, the long-toed salamander (Ambystoma macrodactylum) and Columbia spotted frog (Rana luteiventris), across three spatial scales: water bodies, small catchments and large catchments.

Location Mountain lakes at $\geq 1500 \mathrm{~m}$ elevation were surveyed across the northern Rocky Mountains, USA.

Methods We surveyed 2267 water bodies for amphibian occupancy (based on evidence of reproduction) and fish presence between 1986 and 2002 and modelled the probability of amphibian occupancy at each spatial scale in relation to habitat availability and quality and fish presence.

Results After accounting for habitat features, we estimated that A. macrodactylum was 2.3 times more likely to breed in fishless water bodies than in water bodies with fish. Ambystoma macrodactylum also was more likely to occupy small catchments where none of the water bodies contained fish than in catchments where at least one water body contained fish. However, the probability of salamander occupancy in small catchments was also influenced by habitat availability (i.e. the number of water bodies within a catchment) and suitability of remaining fishless water bodies. We found no relationship between fish presence and salamander occupancy at the large-catchment scale, probably because of increased habitat availability. In contrast to A. macrodactylum, we found no relationship between fish presence and $R$. luteiventris occupancy at any scale.

Main conclusions Our results suggest that the negative effects of non-native salmonids can extend beyond the boundaries of individual water bodies and increase A. macrodactylum extinction risk at landscape scales. We suspect that niche overlap between non-native fish and A. macrodactylum at higher elevations in the northern Rocky Mountains may lead to extinction in catchments with limited suitable habitat.

\section{Keywords}

Ambystoma macrodactylum, amphibian decline, biological invasions, fish stocking, landscape, mountain lake, Rana luteiventris.

\section{INTRODUCTION}

Non-native fishes have contributed to the decline of amphibian populations throughout the world (reviewed by Kats \& Ferrer, 2003). Populations of frogs and salamanders are often much smaller or have been extirpated from water bodies where nonnative, predatory fish have been introduced compared with neighbouring fishless waters (e.g. Hayes \& Jennings, 1986; Bradford, 1989; Braña et al., 1996; Knapp \& Matthews, 2000; Bosch et al., 2006; Welsh et al., 2006). This pattern is 
particularly apparent in montane lakes where fish were absent before human intervention. When fish are experimentally removed from these waters bodies, amphibian populations grow rapidly, approaching population sizes found in nearby fishless waters (Hoffman et al., 2004; Vredenburg, 2004; Knapp et al., 2007; Pope, 2008). Predation is the most likely mechanism by which non-native salmonids suppress amphibian populations (Hoffman et al., 2004; Vredenburg, 2004), but competition, disease and predator avoidance may also be factors.

Most fish-amphibian studies have focused only on effects in individual water bodies. Yet the effects of non-native fish may extend beyond the scale of single water bodies and affect amphibian distributions within broader landscapes including areas where some water bodies remained fishless. These landscape-scale effects have only begun to be examined. For example, Pilliod \& Peterson (2001) found that non-native salmonids suppressed frog populations in fishless water bodies in catchments where the only suitable overwintering habitats were occupied by fish. Frogs would leave fishless breeding sites in the fall, travel to deep, fish-occupied lakes to overwinter, and few would return the following spring compared to frogs that were able to travel to deep, fishless overwintering sites. Densities of adult and juvenile frogs (i.e. those that had overwintered at least once) in fishless water bodies could be predicted by the proportion of water body surface area in a catchment that contained fish. This and other studies (Bradford et al., 1993; Knapp \& Matthews, 2000; Knapp et al., 2003) have suggested that non-native fish might adversely affect amphibian distributions within broader landscapes, but to date, none has examined whether non-native fish may decrease the probability of amphibian occupancy across entire catchments.

There are several ways in which fish might reduce amphibian persistence across a landscape. Fish may decrease the quality of certain critical habitats (e.g. breeding locations, areas with high prey abundance, places to survive winter) through excessive predation or by causing amphibians to avoid them (Resetarits \& Wilbur, 1989; Kats \& Sih, 1992; Hopey \& Petranka, 1994; Pilliod et al., 2002; Vredenburg, 2004). This can result in landscape-scale effects if amphibian populations in fishless water bodies experience predation or other negative fish-effects when individuals temporarily or seasonally move into neighbouring water bodies with fish (Pilliod et al., 2002). Introduced fish may facilitate other amphibian predators, such as garter snakes, resulting in increased predation throughout a catchment (Pope et al., 2008). If remaining fishless water bodies provide only marginal habitat for amphibians, then populations may be small and prone to extinction (Gilpin \& Soule, 1986). Fish in streams or intervening lakes may interfere with animals' ability to travel among critical resources in a landscape, isolate populations in remaining fishless waters, or prevent recolonization (Bradford et al., 1993; Knapp et al., 2003). Thus, amphibian extinction risk would likely increase across the landscape in the presence of non-native fish (Sjogren, 1991).
The goal of this study was to investigate whether 50-100 years of stocking non-native predatory fish into highelevation waters might affect amphibian distributions at multiple spatial scales and not just in the water bodies in which they were stocked. We compiled multiple original data sets from across the northern Rocky Mountains to test three hypotheses related to occupancy of the long-toed salamander (Ambystoma macrodactylum) and Columbia spotted frog (Rana luteiventris). First, we hypothesized that, in congruence with previous studies, these amphibians are less likely to occupy water bodies containing salmonids compared to fishless water bodies. Second, we hypothesized that these amphibians are less likely to occupy catchments where at least one water body contains fish compared with catchments that are devoid of fish. Third, given that the second hypothesis was supported, we hypothesized that the absence of amphibians from catchments with fish was a function of one of the following conditions: (1) amphibians were absent from the catchments before fish were introduced, (2) fish occupy all water bodies suitable for amphibians or (3) some remaining fishless habitats are suitable for amphibians, but fish increase amphibian extinction risk through various indirect processes. Catchments devoid of non-native fish were considered 'reference' catchments and allowed us to better understand amphibian habitat associations prior to fish introductions and whether fishless water bodies in catchments with fish provided suitable habitat for amphibians. Although we were not able to directly address all of these alternative hypotheses (e.g. there are no data on amphibian distributions prior to fish introductions), we examined the weight of evidence for each given the available data.

\section{METHODS}

\section{Study area}

The data for this study came from 10 mountain lake studies from 16 US National Forests, Glacier National Park and a few other private, state and federal lands across the northern Rocky Mountains (Fig. 1). The study area spanned western Montana (west of the Little Belt Mountains), central and northern Idaho (north of the Snake River), and eastern Oregon (Blue and Wallowa mountain ranges). Most, but not all, study catchments were selected randomly. Water bodies were defined as any lentic habitat $>0.1$ ha (range 0.1-20 ha). We chose lakes and ponds $\geq 1500 \mathrm{~m}$ elevation to focus the analysis primarily on those water bodies that were historically fishless before salmonids were stocked. This is nearly twice the elevation cut-off used by Bahls (1992) to estimate that $95 \%$ of lakes above $800 \mathrm{~m}$ were historically fishless in 11 western states prior to the initiation of recreational fish stocking programmes in the early 1900s. Thus, we are confident that most lakes in our study were historically fishless prior to the initiation of stocking programmes. However, a few beaver pond complexes along riverine wetlands and a few low-gradient catchments in Montana might have had native bull trout (Salvelinus confluentus) and westslope 
Figure 1 Location of water bodies surveyed in Idaho, Montana and Oregon between 1986 and 2002. Major sub-basins are shown for perspective.

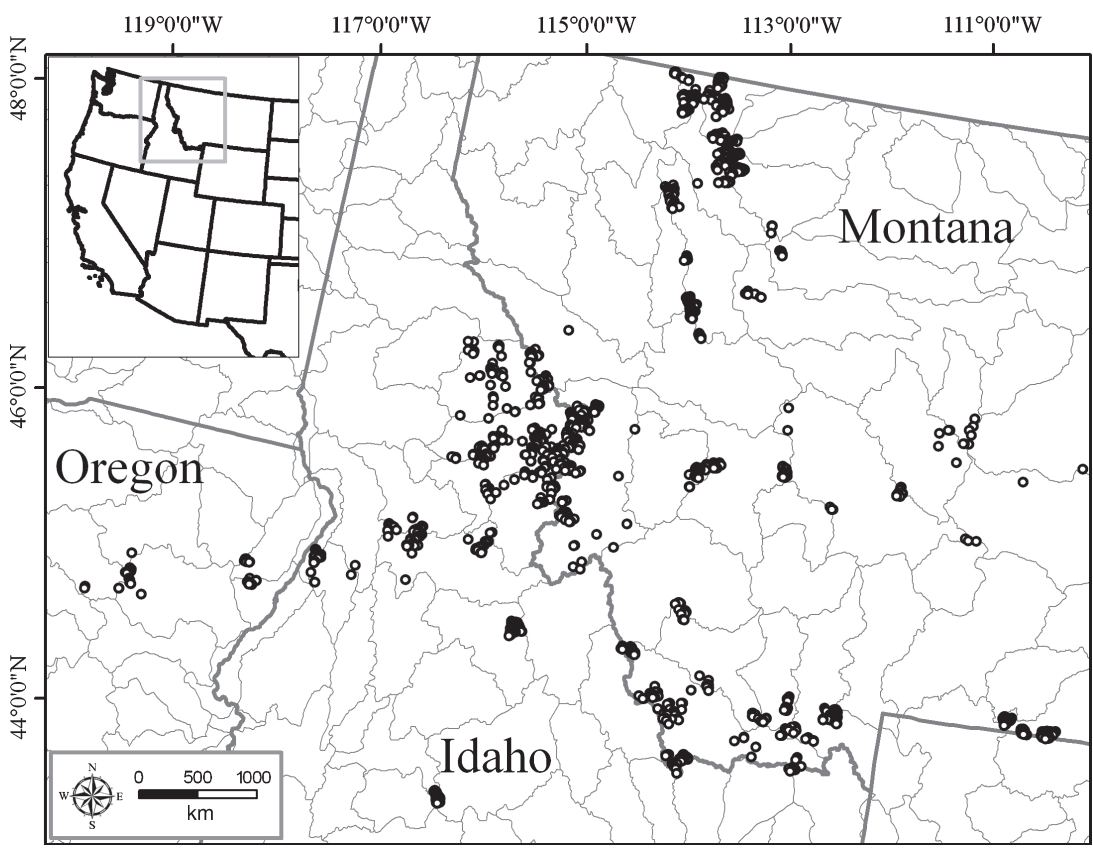

cutthroat trout (Oncorhynchus clarki). In all, these represent $<1 \%$ of all water bodies sampled. Therefore, we considered the high-elevation water bodies used in this study as locations where amphibians likely had not been exposed to fish since post-glacial colonization, making them appropriate locations to understand the effects of non-native fish on amphibian decline and extinction risk.

\section{Target species}

Ambystoma macrodactylum and R. luteiventris are the two most common amphibians in the region. Both species respond to predatory fishes where they co-occur with them (Tyler et al., 1998a; Pilliod \& Peterson, 2001; Bull \& Marx, 2002; Welsh et al., 2006; Pearson \& Goater, 2008), but differences in life history characteristics between A. macrodactylum and R. luteiventris could result in different sensitivities to predatory fish. Both amphibians breed in lakes and ponds ranging from sea level to nearly 3000-m elevation. Above $1500 \mathrm{~m}$, both species deposit eggs from May to July and embryos hatch in 7-21 days (Pilliod \& Fronzuto, 2005; Reaser \& Pilliod, 2005). Ambystoma macrodactylum larvae feed on benthic and water column invertebrates and reach metamorphosis in 2 months to 3 years depending on depth, temperature and elevation (Pilliod \& Fronzuto, 2005). In water bodies with fish, salamander larvae hide in protective cover to avoid predation, potentially resulting in reduced growth rates (Tyler et al., 1998b). Adults and post-metamorphic juveniles live and hibernate terrestrially. Larvae of $R$. luteiventris typically feed on filamentous algae and other types of periphyton in the shallow margins of lakes and ponds and thus may be less exposed to predatory fish. Furthermore, R. luteiventris tadpoles metamorphose in 30-60 days and do not overwinter (Reaser \& Pilliod, 2005). Recently metamorphosed, juvenile ( $1-3$ years old) and adult frogs overwinter in water bodies that do not freeze to the bottom and have adequate dissolved oxygen (Bull \& Hayes, 2002). These deeper water bodies are typically where introduced salmonids now occur (Knapp \& Matthews, 2000; Pilliod \& Peterson, 2001; Knapp, 2005).

\section{Amphibian surveys}

We delineated catchments using the Pfafstetter Coding System (Verdin \& Verdin, 1999) in ArcGIS 9.0 (ESRI, Redlands, CA, USA). The Pfafstetter Coding System is a hierarchical classification of catchment boundaries on the basis of topology of land surface, especially junctions along a river network (Verdin \& Verdin, 1999; Poppenga \& Worstell, 2008). Higher levels represent ever-finer tessellations of the land surface into smaller catchments. We subdivided our landscape into large and small catchments (Fig. 2). Large catchments that were not subdivided into nested smaller catchments by the Pfafstetter Coding System were assigned to either the large-catchment or small-catchment data set to avoid the analytical issues of individual catchments appearing in both analyses. To determine which undivided catchments would be included in each analysis, we assigned undivided catchments as either 'small' or 'large' on the basis of its area. Catchments larger than the area of the smallest large catchment that was subdivided were included in the large-catchment analyses and catchments that were smaller than the area of the smallest large catchment that was subdivided were included in the small-catchment analyses.

We are confident that nearly all water bodies were searched within small catchments, but less confident that complete inventories were successful for large catchments because of their large extent and rugged topography. In most cases, water bodies were first identified through the examination of National Wetlands Inventory maps, aerial photographs and 


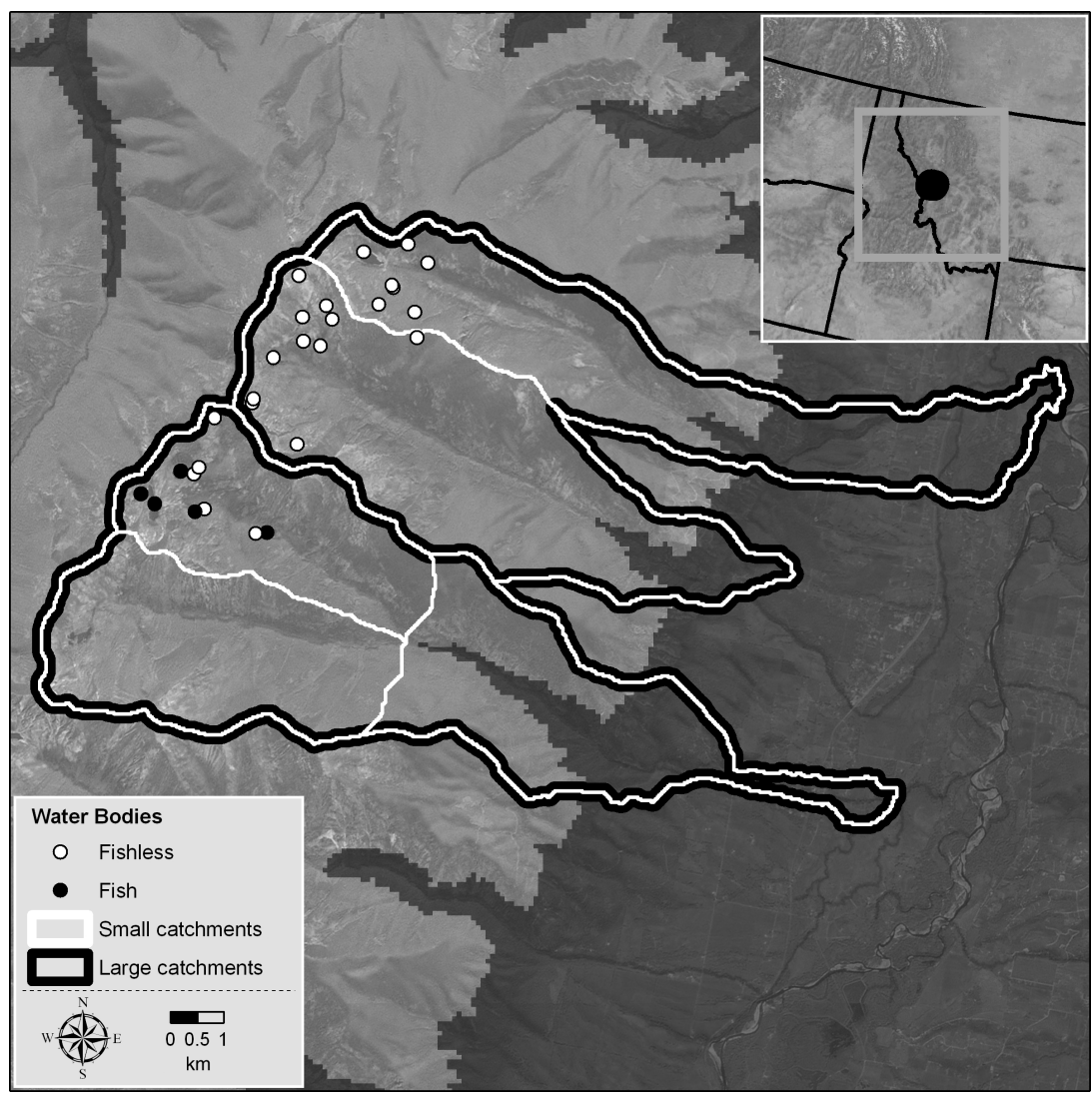

Figure 2 Example of small catchments nested within large catchments. Water bodies are indicated as with fish (fill circles) and without fish (open circles). The light grey background represents the proportion of catchments $>1500 \mathrm{~m}$ elevation. The area of catchments $<1500 \mathrm{~m}$ elevation (dark grey) were excluded from this study. topographic maps prior to field visits. All potential wetland areas were searched in the field, and water bodies discovered incidentally were included in the study set. Any catchment that was not comprehensively surveyed was excluded from catchment-scale analyses. Water bodies that occurred in catchments where no amphibians (any life stage) or fish were detected were excluded from water body-scale analyses.

We defined occupancy of A. macrodactylum and R. luteiventris at a water body on the basis of reproduction (i.e. observing eggs or larvae) during visual encounter surveys (Crump \& Scott, 1994; Thoms et al., 1997). Surveys were conducted while amphibian larvae were expected to be present, usually from ice-out (June in most locations) through early September. Of 2267 water bodies surveyed, $81 \%$ were surveyed once, $15 \%$ were surveyed $2-5$ times and $4 \%$ were surveyed $>5$ times. A species was considered present in a water body if reproduction was detected during any survey and present in a catchment if reproduction was detected in any water body in the catchment during any survey. Although both species have conspicuous eggs and larvae, particularly in clear, oligotrophic mountain lakes, we recognize that occupancy determination could be affected by detection rates and breeding dynamics where species do not breed every year. We evaluated detection probabilities for each species by analysing a subset of our data where multiple visits were conducted within a year and over multiple years using the program PRESENCE. We used observed species occupancy, instead of estimated occupancy, in the final analyses.

\section{Fish surveys}

The occurrence of fish in a water body was determined by overnight gill net sets or visual observation and confirmed with state stocking records and fishery surveys. We hereafter use the capitalized word FISH to refer to the variable that denotes whether fish were present or not detected in a water body. We used program PRESENCE to estimate the detectability of fish at a subset of lakes with multiple visits to provide a measure of certainty.

\section{Habitat descriptions}

We recorded standardized habitat characteristics at each water body and refer to habitat variables used in models with capitalized abbreviations. During site visits, we used 1:24,000 US Geological Survey topographic maps or global positioning systems to record geographic coordinates (Universal Transverse Mercator, UTM) and elevation (ELEV) at the outlet of each water body. Site coordinates were converted to a common system to avoid problems with different datums and zones. We estimated maximum water depth at each water body (DEPTH) as $0-1,1-2$ and $>2 \mathrm{~m}$ using sonar, plumb-lines or visual inspection. Primary substrate of the littoral zone (SUBS) was defined as fine (organic, silt and sand) or coarse (gravel, cobble and boulder). We visually estimated the percentage of shoreline perimeter with emergent vegetation (VEG) as $0-5 \%$, $6-25 \%, 26-50 \%$ and $>50 \%$. Water temperature was not 
measured directly because the diel and seasonal variability in water temperature is impossible to capture with spot measurements during 1-2 site visits that last only a few hours. As a surrogate for water temperature, we calculated the average solar radiation (SUN) striking one point in each water body using a modified solar radiation index model in a GIS (Kumar et al., 1997). Solar index values were calculated as a brightness value (0-255) averaged across four times (10:00, 12:00, 14:00 and $16: 00)$ on 4 days $(6 / 15,7 / 15,8 / 15$ and $9 / 15)$. This model did not adjust for shading from trees, but did account for shading from surrounding mountain ridges. Habitat variables collected by different investigators in different studies were recoded into common units or categories.

\section{Data analysis}

We analysed data at three nested spatial scales: water body, small catchments and large catchments. Analyses were restricted to water bodies and catchments within the range of the species; A. macrodactylum does not occur in the southeastern part of the study area (Stebbins, 2003), so sample sizes for this species were slightly smaller.

Water bodies that support fish are often different than those without fish, which can confound analyses of co-occurrence. To address this discrepancy, we included a variable for fish presence into each of four habitat models, resulting in eight competing models. The habitat models were developed a priori using information on the habitat associations of these species from the literature and expert opinion (Anderson, 1967; Munger et al., 1998; Tyler et al., 1998a; Adams et al., 2001; Bull \& Marx, 2002; Murphy, 2002; Pilliod et al., 2002; Palen et al., 2005; Pearl et al., 2007).

\section{Water body models}

Water body models related the local habitat characteristics of each water body to the probability of amphibian occupancy (i.e. a breeding population). We included a spatial location term for each water body in all water body models to account for expected autocorrelation in habitat features and the distribution of populations. This location variable was calculated as a smooth surface of UTM easting and northing values using a loess (locally weighted polynomial regression) smoother because of its advantages for spatially correlated data (Hobert et al., 1997; Knapp et al., 2003). Loess fits the data using weighted least squares, giving more weight to data nearest geographically to the point whose response is being estimated and less weight to data further away. We used a span window of 0.5 to define how much of the data was used to fit each local polynomial (Hastie \& Tibshirani, 1990).

We examined eight water body models for each species. Habitat and Habitat + Fish models represented the global models and included all habitat variables. Temperature and Temperature + Fish models were hypothesized to be good predictors of A. macrodactylum and R. luteiventris breeding because the duration of warm water temperatures is important for water body productivity and growth rates for larval life stages (Smith-Gill \& Berven, 1979). These models also included ELEV because of its importance to local climate and the distribution of multiple amphibian species across the West (Adams et al., 2005). Cover and Cover + Fish models were hypothesized to be important to the breeding success of both species because they use emergent vegetation for oviposition (Bull \& Marx, 2002; Palen et al., 2005; Pearl et al., 2007). In the Cover + Fish model, we included an interaction of vegetation (VEG) and fish presence (FISH) because vulnerable aquatic life stages can avoid predation when sufficient cover is available (Tyler et al., 1998b). The Depth and Depth + Fish models examined the effect of habitat differences between shallow ponds and deep lakes. We included an interaction of ELEV and DEPTH in the A. macrodactylum models because the maximum water depth requirements for successful overwintering of larvae increase with elevation (Anderson, 1967). The ELEV by DEPTH interaction was not included in $R$. luteiventris models because its larvae do not overwinter and metamorphosed frogs can travel terrestrially to other nearby water bodies (Pilliod et al., 2002).

\section{Catchment models}

Catchment models examined the relationship between landscape characteristics and amphibian occupancy (i.e. occurrence of at least one breeding population) of a catchment. We examined four pairs of catchment models at each landscape scale: small and large catchments. The presence or absence of fish in at least one water body in a catchment (FISHSTATUS) was added to each model to determine what additional variation could be explained by fish after accounting for landscape characteristics among catchments. The Elevation Model included a predictor variable for the average elevation (aELEV) of the catchment. The Isolation Model included a predictor variable for the average distance to nearest water body within a catchment (aDIST). The Size Model provided a measure of the amount of potential habitat per catchment, including total area of a catchment (AREA) and number of water bodies in a catchment (SITES). The Full Model included all variables. Smaller sample sizes in catchment analyses prohibited us from including a geographic location term in catchment models (i.e. UTM).

We did not expect linear relationships between species occupancy and covariates. Therefore, we used generalized additive models (GAMs) for analyses. GAMs are a nonparametric extension of generalized linear models that use a smoothing function to describe the relationships between predictor and response variables (Cleveland \& Devlin, 1988; Hastie \& Tibshirani, 1990). A cubic smoothing spline was applied to all continuous variables, except UTM, to allow for a nonparametric fit between predictor and response variables. We used loess smoothing with the UTM variable.

Selection of the best of the candidate models at each spatial scale was determined on the basis of differences in the secondorder Akaike information criterion (AICc) and model weights 
(w) (Burnham \& Anderson, 2002). The best model from the set of models had the lowest AICc value and only models $\leq 2$ AIC units from this top model were considered competitive. Model weights represent the probability that a model is the best of those being considered for the dataset (Burnham \& Anderson, 2002). Model weights were summed separately for all models that contained fish and compared to those that did not contain fish to use the combined weight of evidence as a tool in determining the importance of fish as a predictor variable (Burnham \& Anderson, 2002). We used coefficients from the highest ranked model to graph the effect of fish presence and other habitat and landscape characteristics on amphibian occupancy. The importance of variables was assessed by examining whether the $95 \%$ confidence intervals (CI) overlapped zero. Odds ratios for the fish parameter (FISH and FISHSTATUS) were calculated from the best supported model (Hosmer \& Lemeshow, 1989). If the 95\% confidence limits for odds of detecting amphibian reproduction included 1.0, then fish were considered to have little effect on amphibian presence. We estimated a single variance inflation factor (c) by dividing the goodness-of-fit chi-square statistic of the global model by its degrees of freedom (Burnham \& Anderson, 2002). In general, model structure was acceptable and the data were not overdispersed $(\hat{c} \leq 1.3)$. All GAMs were conducted in SPLUS 6.1.

\section{Indirect effects of non-native fish on amphibian occupancy}

To determine if the presence of non-native fish in at least one water body in a catchment (FISHSTATUS) has an effect on the probability of amphibian occupancy within fishless water bodies (i.e. an indirect effect of fish), we performed nonparametric multiplicative regression (NPMR) analyses for each species (McCune, 2006, 2009). These analyses allowed us to determine (1) the most important water body-level habitat variables (ELEV, SUN, DEPTH, SUBS and VEG) for predicting amphibian occupancy in fishless water bodies, (2) how these variables interact in non-additive, nonlinear ways to influence occupancy and (3) whether FISHSTATUS influences the probability of amphibian occupancy in fishless water bodies after accounting for differences in amphibian habitat quality.
The NPMR analyses were performed using the local mean model with Gaussian weighting functions in HyPERNiche 2.06 software (McCune \& Mefford, 2009). We assessed model fit using $\log$ likelihood ratios ( $\log \beta$ values) to evaluate the improvement of each fitted model over the naïve or null model (i.e. overall species occupancy rate in the data set). We included FISHSTATUS in all models and conducted a free search for all possible combinations of predictor variables and tolerances. Tolerance is the standard deviation of the Gaussian weighting function for a given predictor variable. A variable was included in the final model if its inclusion resulted in a $\geq 10 \%$ increase in $\log \beta$.

For the best model predicting occupancy of fishless water bodies for each species, we reported average neighbourhood size $\left(N^{*}\right.$; average number of sample units contributing to the estimate of occupancy at each point on the modelled surface), tolerance for each predictor variable (low tolerance indicates that species occupancy is restricted to a narrow portion of the environmental or predictor gradient) and sensitivity for each predictor. Sensitivity is a measure of the relative importance of each predictor in estimating occupancy probability, where a sensitivity of one indicates that, on average, changing the value of the predictor by $\pm 5 \%$ of its range changes the response by an equal magnitude and a sensitivity of zero indicates that changing the predictor does not change the response value (McCune, 2009).

\section{RESULTS}

Between 1986 and 2002, we sampled 2267 water bodies for fish and amphibians in 149 large and 315 small catchments (Table 1). Fifteen large and 55 small catchments did not contain fish or amphibians. Small catchments ranged in size from 0.8 to $63.1 \mathrm{~km}^{2}$ (median $9.3 \mathrm{~km}^{2}$ ) and large catchments from 9.6 to $137.4 \mathrm{~km}^{2}$ (median $27.0 \mathrm{~km}^{2}$ ). There was a weak correlation between the size of large catchments and the number of water bodies within the catchment $\left(r^{2}=0.28\right)$, but no comparable relationship for small catchments $\left(r^{2}=0.03\right)$.

Fish were detected in 27\% (607 of 2267) of the water bodies, $44 \%$ of the small catchments ( 140 of 315 ) and $60 \%$ ( 89 of 149) of the large catchments (Table 1). Although fish species composition was not recorded in all lakes, the following species were detected and generally agree with state stocking

Table 1 Number of water bodies and catchments sampled relative to fish presence.

\begin{tabular}{|c|c|c|c|c|c|c|}
\hline \multirow[b]{2}{*}{ Dataset } & \multirow[b]{2}{*}{ Spatial scale } & \multicolumn{2}{|l|}{ Fish } & \multicolumn{2}{|c|}{ Amphibians } & \multirow[b]{2}{*}{ Total } \\
\hline & & Present & Not detected & Present & Not detected & \\
\hline \multirow[t]{3}{*}{ Within range of Ambystoma macrodactylum } & Number of water bodies & 492 & 1186 & 523 & 1155 & 1678 \\
\hline & Number of small catchments & 113 & 109 & 126 & 96 & 222 \\
\hline & Number of large catchments & 76 & 38 & 91 & 23 & 114 \\
\hline \multirow[t]{3}{*}{ Within range of Rana luteiventris } & Number of water bodies & 607 & 1660 & 643 & 1624 & 2267 \\
\hline & Number of small catchments & 140 & 175 & 177 & 138 & 315 \\
\hline & Number of large catchments & 89 & 60 & 111 & 38 & 149 \\
\hline
\end{tabular}


records for most areas: westslope and Yellowstone cutthroat trout (Oncorhynchus clarki lewisi and Oncorhynchus clarki bouvieri), rainbow trout (Oncorhynchus mykiss), golden trout (Oncorhynchus m. aguabonita), bull trout (S. confluentus), brook trout (Salvelinus fontinalis) and arctic grayling (Thymallus arcticus). Hybrid trout were also reported. Of the water bodies with fish, $74 \%$ were lakes $>2 \mathrm{~m}$ deep. Detection rate was 0.89 for water bodies visually surveyed for fish 2-5 times and 1.0 for lakes surveyed visually followed by overnight gillnet sets.

\section{Effects of non-native fish on amphibian occupancy in water bodies}

We detected evidence of reproduction (= occupancy) for A. macrodactylum at 31\% (523 of 1678) and R. luteiventris at $28 \%$ (643 of 2267) of water bodies sampled (Table 1). The average single visit probability of detection given presence $(P)$ was $0.74( \pm 0.12 \mathrm{SE})$ for $A$. macrodactylum and $0.91( \pm 0.07 \mathrm{SE})$ for $R$. luteiventris at a subset of water bodies where multiple visits were conducted within the same year.

Amphibian occupancy relative to fish presence in a water body varied by amphibian species. The estimated effect of fish presence on A. macrodactylum occupancy was negative in individual water bodies (Fig. 3a). Ambystoma macrodactylum was 2.3 (odds ratio 95\% CI $=1.39-3.87$ ) times more likely to be detected in fishless water bodies than in water bodies with fish. Habitat + Fish was the top-ranked model and received 95.9\% of model weight, whereas the Habitat Model received none (Table 2). Rana luteiventris occupancy was unrelated to fish presence (Fig. 4a). The Habitat + Fish Model received the most support $(w=0.819)$, but frogs were just as likely to be detected in water bodies with fish than in fishless water bodies (Table 3, odds ratio $=0.78,95 \% \mathrm{CI}=0.45-1.35$ ).

Water body habitat characteristics were also important predictors of amphibian occupancy. Both species were more likely to occur in water bodies that were at lower elevations (i.e. below $2400 \mathrm{~m}$ ), had more solar exposure (e.g. not in north-facing cirques), had predominantly silt, mud or sand substrates in the littoral zone and had at least $26 \%$ shoreline with emergent vegetation (Figs $3 \& 4$ ). Ambystoma macrodactylum had a weak negative association with water bodies $>2 \mathrm{~m}$ deep (Fig. 3d). Rana luteiventris was most likely to breed in water bodies 1-2 m deep (Fig. 4d) and was strongly associated with shoreline vegetation (Fig. 4f).

\section{Effects of non-native fish on amphibian occupancy in catchments}

The presence of fish in at least one water body in small catchments (i.e. catchment-level fish presence or FISHSTATUS) was negatively associated with the probability of A. macrodactylum occupancy in a catchment (Table 4, Fig. 5a). The Size + Fish status models were the top-ranked models for A. macrodactylum at the small catchment scale $(w=0.708$; Table 4). Salamanders were more likely to occupy small catchments with $>3$ water bodies and $>12 \mathrm{~km}^{2}$ in area (Fig. 5b,c). The probability of salamander occupancy in small (a)

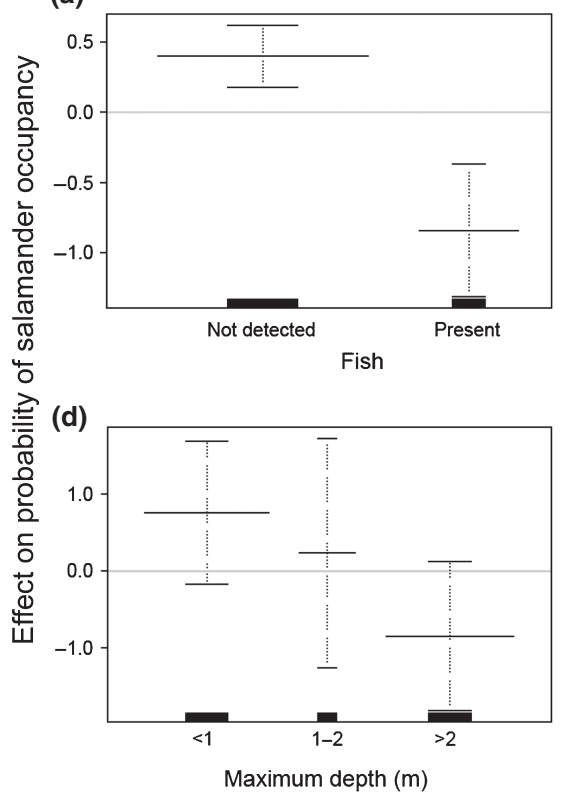

(b)

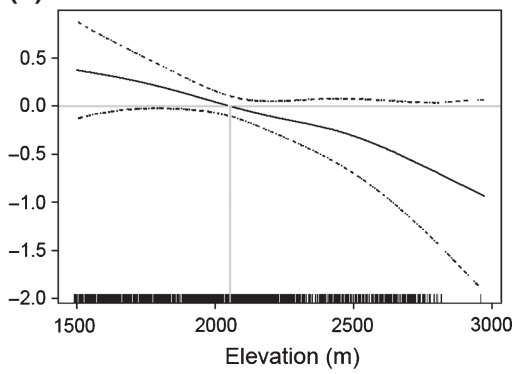

(e)

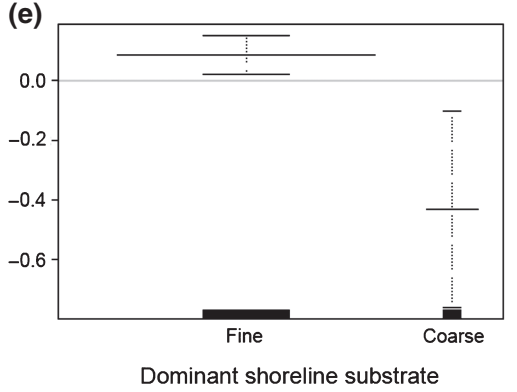

(c)

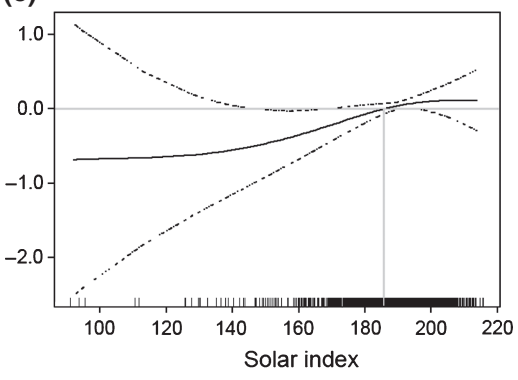

(f)

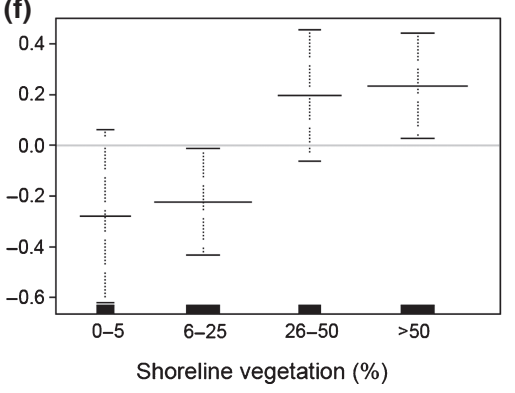

Figure 3 (a-f) Estimated effect of habitat variables on probability of Ambystoma macrodactylum occupancy (breeding) in 1536 water bodies in the northern Rocky Mountains. The dotted lines or error bars in each plot are approximate 95\% pointwise confidence intervals (CI). Hatch marks at the bottom of each graph represent data points. Significance is indicated when estimated $95 \%$ CIs fall completely above or below the no-effect line at zero (light grey horizontal line). A vertical light grey line drawn down to the $x$-axis indicates an approximate threshold in the predictor variable where effects on occupancy transition from positive to negative or vice versa. 
Table 2 Models predicting Ambystoma macrodactylum occupancy in water bodies.

\begin{tabular}{llrrrr}
\hline Model name & Model parameters & \multirow{2}{*}{$\begin{array}{c}\text { Deviance } \\
\text { NAICc }\end{array}$} & $W_{i}$ \\
\hline Habitat + Fish & UTM + ELEV + SUN + DEPTH + ELEV:DEPTH + SUBS + VEG + FISH + VEG:FISH & 24 & 1671.4 & 0.00 & 0.959 \\
Temperature + Fish & UTM + ELEV + SUN + DEPTH + ELEV:DEPTH + FISH & 17 & 1692.8 & 6.92 & 0.030 \\
Depth + Fish & UTM + DEPTH + FISH & 15 & 1698.9 & 9.02 & 0.011 \\
Cover + Fish & UTM + SUBS + VEG + FISH + VEG:FISH & 16 & 1728.0 & 40.16 & 0.000 \\
Habitat & UTM + ELEV + SUN + DEPTH + ELEV:DEPTH + SUBS + VEG & 20 & 1814.9 & 135.28 & 0.000 \\
Cover & UTM + SUBS + VEG & 12 & 1839.2 & 143.18 & 0.000 \\
Depth & UTM + DEPTH & 14 & 1840.3 & 148.43 & 0.000 \\
Temperature & UTM + ELEV + SUN + DEPTH + ELEV:DEPTH & 16 & 1837.1 & 149.27 & 0.000 \\
\hline
\end{tabular}

Model description: $n=1536$ water bodies, null deviance $=1970.27, \hat{c}=1.11$.

AICc, Akaike information criterion; UTM, UTM easting and northing as a smooth surface; DEPTH, maximum water depth; ELEV, elevation; ELEV:DEPTH, interaction of DEPTH and ELEV; SUBS, dominant substrate in the water body; VEG, percentage of shoreline with emergent vegetation; SUN, solar radiation index; FISH, presence of non-native salmonids.
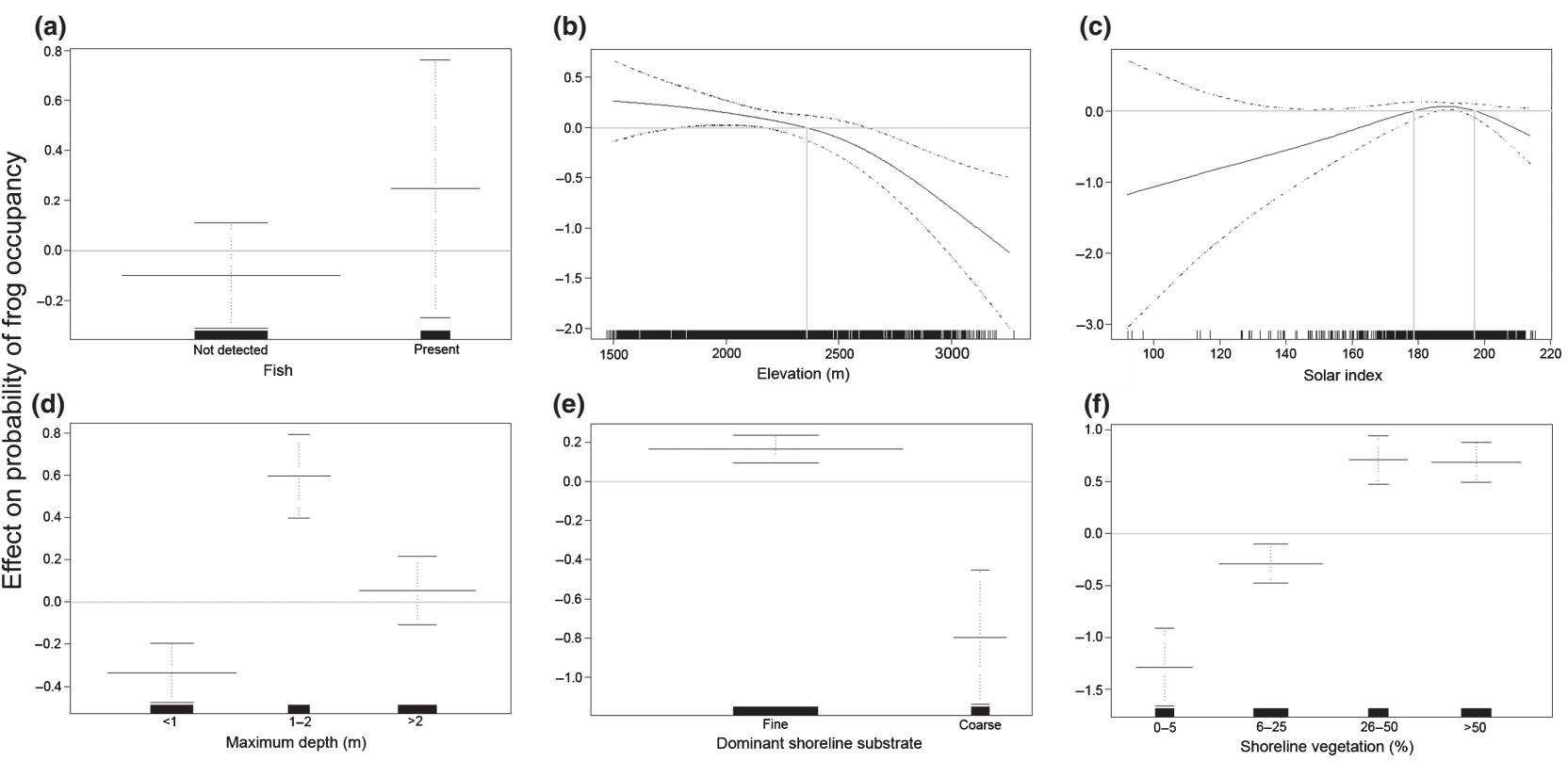

Figure 4 (a-f) Estimated effect of habitat variables on probability of Rana luteiventris occupancy (breeding) in 2093 water bodies in the northern Rocky Mountains. The dotted lines or error bars in each plot are approximate 95\% pointwise confidence intervals (CI). Hatch marks at the bottom of each graph represent data points. Significance is indicated when estimated 95\% CIs fall completely above or below the no-effect line at zero (light grey horizontal line). A vertical light grey line drawn down to the $x$-axis indicates an approximate threshold in the predictor variable where effects on occupancy transition from positive to negative or vice versa.

catchments increased logarithmically with the number of water bodies in a catchment (Fig. 6; $y=0.1299 \operatorname{Ln}(x)+0.4988$ for fishless catchments $\left[r^{2}=0.67\right]$ and $y=0.1507 \operatorname{Ln}(x)+0.3275$ for catchments with fish $\left.\left[r^{2}=0.71\right]\right)$. There was model uncertainty for A. macrodactylum at the large-catchment scale and no influence of FISHSTATUS at this scale (Table 5; Table S1 in Supporting Information).

In contrast, the probability of $R$. luteiventris occupancy in small catchments was not associated with FISHSTATUS (Table S2, Fig. S2). The Size Model was the top-ranked model for $R$. luteiventris at the small-catchment scale (Table 5). The Size + Fish and Size models were both competitive models predicting the occupancy of $R$. luteiventris in large catchments, and FISHSTATUS was positively associated with frog occupancy at this scale (Table S3, Fig. S3).

\section{Indirect effects of non-native fish on amphibian occupancy}

FISHSTATUS, ELEV and DEPTH were the best predictors of A. macrodactylum occupancy in fishless water bodies (Table 6). This model represented a $20 \%$ increase in $\log \beta$ over the model containing only FISHSTATUS and ELEV. The next best three factor model had a $\log \beta 3 \%$ lower than the selected 
Table 3 Models predicting Rana luteiventris occupancy in water bodies.

\begin{tabular}{|c|c|c|c|c|c|}
\hline Model name & Model parameters & $k$ & Deviance & $\Delta \mathrm{AICc}$ & $W_{i}$ \\
\hline Habitat + Fish & UTM + ELEV + SUN + DEPTH + SUBS + VEG + FISH + VEG:FISH & 21 & 2095.7 & 0.00 & 0.819 \\
\hline Habitat & UTM + ELEV + SUN + DEPTH + SUBS + VEG & 17 & 2106.9 & 3.02 & 0.180 \\
\hline Cover + Fish & UTM + SUBS + VEG + FISH + VEG:FISH & 17 & 2118.9 & 14.99 & 0.000 \\
\hline Cover & $\mathrm{UTM}+\mathrm{SUBS}+\mathrm{VEG}$ & 13 & 2129.3 & 17.30 & 0.000 \\
\hline Temperature + Fish & $\mathrm{UTM}+\mathrm{ELEV}+\mathrm{SUN}+\mathrm{DEPTH}+\mathrm{FISH}$ & 14 & 2289.3 & 179.33 & 0.000 \\
\hline Temperature & $\mathrm{UTM}+\mathrm{ELEV}+\mathrm{SUN}+\mathrm{DEPTH}$ & 13 & 2302.6 & 190.63 & 0.000 \\
\hline Depth + Fish & $\mathrm{UTM}+\mathrm{DEPTH}+\mathrm{FISH}$ & 10 & 2364.1 & 245.97 & 0.000 \\
\hline Depth & $\mathrm{UTM}+\mathrm{DEPTH}$ & 9 & 2370.5 & 250.40 & 0.000 \\
\hline
\end{tabular}

Model description: $n=2093$ water bodies, null deviance $=2582.15, \hat{c}=1.01$.

AICc, Akaike information criterion; UTM, UTM easting and northing as a smooth surface; DEPTH, maximum water depth; ELEV, elevation; SUBS, dominant substrate in the water body; VEG, percentage of shoreline with emergent vegetation; SUN, solar radiation index; FISH, presence of nonnative salmonids.

(a)

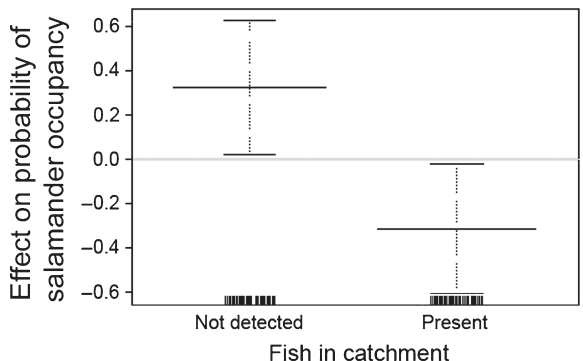

(b)

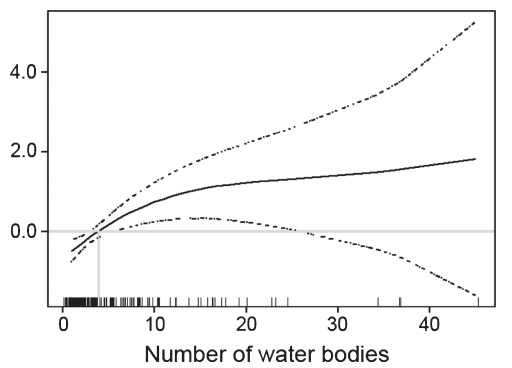

(c)

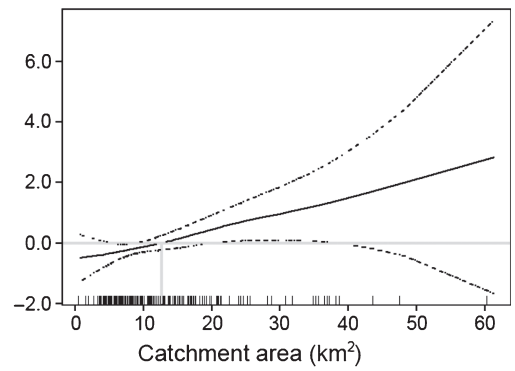

Figure $5(\mathrm{a}-\mathrm{c})$ Estimated effect of landscape variables on probability of Ambystoma macrodactylum breeding occurrence in 222 small catchments in the northern Rocky Mountains. The dotted lines or error bars in each plot are approximate $95 \%$ pointwise confidence intervals (CI). Hatch marks at the bottom of each graph represent data points. Significance is indicated when estimated $95 \%$ CIs fall completely above or below the no-effect line at zero (light grey horizontal line). A vertical light grey line drawn down to the $x$-axis indicates an approximate threshold in the predictor variable where effects on occurrence transition from positive to negative or vice versa.

model. The probability of A. macrodactylum occupancy in fishless water bodies was best predicted by a nonlinear interaction between ELEV and DEPTH (Fig. 7), with ELEV having a greater influence than DEPTH (Table 6; sensitivity 0.79 vs. 0.13 ). The highest probability of occupancy occurred between 1900 and $2400 \mathrm{~m}$ elevation in water bodies $>2 \mathrm{~m}$ deep and decreased in water bodies $1-2 \mathrm{~m}$ and $<1 \mathrm{~m}$ deep. For nearly all comparable combinations of ELEV and DEPTH, the probability of salamander occupancy in fishless water bodies was greater in fishless catchments than in catchments where at least one water body contained fish. Fish have a greater indirect effect on salamander occupancy at higher elevations (e.g. 2400-2500 m) in shallower water bodies. At lower elevations (e.g. 1500-1600 m), FISHSTATUS and DEPTH had little effect on the probability of salamander occupancy in fishless water bodies (Fig. 7).

The best model predicting the probability of $R$. luteiventris occupancy in fishless water bodies consisted of FISHSTATUS, VEG and DEPTH (Table 6). Adding DEPTH to the best two factor model (FISHSTATUS and VEG) increased $\log \beta$ by $25 \%$, whereas the next best model increased $\log \beta$ by only $2 \%$ over the final model. Rana luteiventris occupancy in fishless water bodies was more dependent on VEG than on DEPTH (Table 6; sensitivity 0.38 vs. 0.03 ) and increased as VEG increased (Fig. 8). When VEG was $<25 \%$, frog occupancy was higher in water bodies of intermediate depth and occupancy rates were low for both shallow and deep water bodies. However, when VEG was $>25 \%$, occupancy rates were highest for water bodies $>1 \mathrm{~m}$ deep. In these deeper $(>1 \mathrm{~m}$ ) water bodies with $>25 \%$ shoreline vegetation, the probability of frog occupancy was only slightly higher in catchments where fish were not detected than in catchments where fish were present. In catchments where fish were not detected, frog occupancy increased greatly in deep ( $>2 \mathrm{~m}$ ) water bodies as VEG increased beyond $25 \%$. This increase was not observed in fishless water bodies in catchments with fish. In shallow $(<1 \mathrm{~m})$ water bodies, the probability of frog occupancy increased with increasing VEG independent of whether fish were present within the catchment (Fig. 8).

\section{DISCUSSION}

This study adds to a growing body of evidence that the presence of non-native fish may be causing extirpations of 


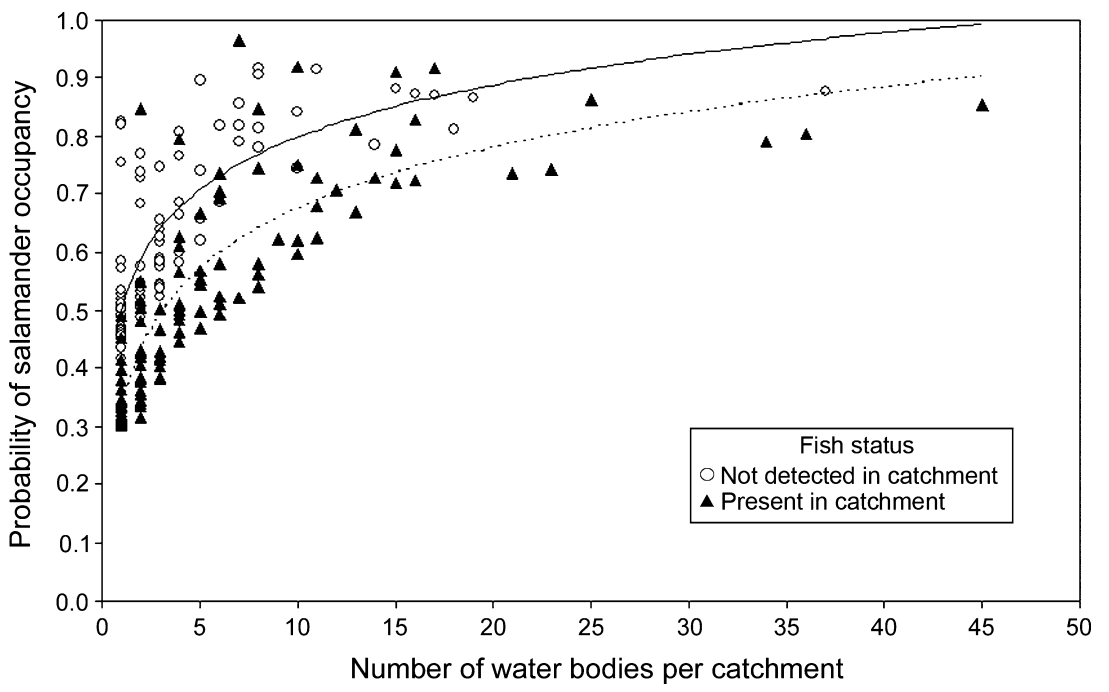

Figure 6 Generalized additive modelled probability of Ambystoma macrodactylum occupancy in small catchments as a function of the number of water bodies in a catchment (SITES) for catchments with and without non-native fish (FISHSTATUS). Lines represent logarithmic function fit to the data in catchments with fish (dashed line) and catchments where fish were not detected (solid line).

Table 4 Models predicting Ambystoma macrodactylum occupancy in small catchments.

\begin{tabular}{|c|c|c|c|c|c|}
\hline Model Name & Model parameters & $k$ & Deviance & $\triangle \mathrm{AICc}$ & $W_{i}$ \\
\hline Size + Fish status & SITES + AREA + FISHSTATUS & 5 & 273.6 & 0.00 & 0.708 \\
\hline Size & SITES + AREA & 4 & 278.7 & 2.93 & 0.164 \\
\hline Full + Fish status & SITES + AREA + aELEV + aDIST + FISHSTATUS & 10 & 265.9 & 3.86 & 0.103 \\
\hline Ful & SITES + AREA + aELEV + aDIST & 9 & 270.8 & 6.64 & 0.026 \\
\hline Isolation & aDIST & 3 & 292.8 & 16.02 & 0.000 \\
\hline Isolation + Fish status & aDIST + FISHSTATUS & 4 & 291.4 & 16.68 & 0.000 \\
\hline Elevation & aELEV & 2 & 302.8 & 22.96 & 0.000 \\
\hline Elevation + Fish status & aELEV + FISHSTATUS & 3 & 301.4 & 23.64 & 0.000 \\
\hline
\end{tabular}

Model description: $n=222$ small catchments, null deviance $=303.69, \hat{\mathrm{c}}=1.27$.

AICc, Akaike information criterion; SITES, number of water bodies per catchment; AREA, size of the catchment; aELEV, average elevation of water bodies in catchment; aDIST, average distance to nearest water body within catchment; FISHSTATUS, presence of non-native salmonids in at least one water body per catchment.

Table 5 The best models selected from each set of models examined at each spatial scale for Ambystoma macrodactylum and Rana luteiventris occupancy. See Tables 2 and 3 for set of water body models and Table 4 and online supplementary material (Tables S1-S3) for full set of models at each catchment scale.

\begin{tabular}{|c|c|c|c|c|c|c|c|}
\hline Species & Spatial scale & $\begin{array}{l}\text { Number of } \\
\text { models }\end{array}$ & $\begin{array}{l}\text { Sample } \\
\text { size }\end{array}$ & $\begin{array}{l}\text { Top model at } \\
\text { spatial scale }\end{array}$ & $\begin{array}{l}\Sigma w \text { (models } \\
\text { with FISH) }\end{array}$ & $\begin{array}{l}\Sigma w(\text { models } \\
\text { without FISH) }\end{array}$ & Effect of fish \\
\hline \multirow[t]{3}{*}{ A. macrodactylum } & Water body & 8 & 1536 & Habitat + Fish & 1.000 & 0.000 & Negative \\
\hline & Small catchment & 8 & 222 & Size + Fish status & 0.811 & 0.189 & Negative \\
\hline & Large catchment & 8 & 114 & Size & 0.250 & 0.750 & Neutral \\
\hline \multirow[t]{3}{*}{ R. luteiventris } & Water body & 8 & 2093 & Habitat + Fish & 0.819 & 0.181 & Neutral \\
\hline & Small catchment & 8 & 315 & Size & 0.378 & 0.622 & Neutral \\
\hline & Large catchment & 8 & 149 & Size + Fish status & 0.953 & 0.047 & Positive \\
\hline
\end{tabular}

amphibians in water bodies where fish have been introduced. More importantly, this study provides evidence that the introduction of non-native fish into mountain environments may also be extirpating some amphibians from entire catchments where fishless habitats still remain. These findings have important conservation implications because they indicate that non-native salmonids could negatively affect the distribution of some native amphibians across fairly large landscapes, possibly leading to range contractions.

Similar to other studies, we found A. macrodactylum was much less likely to breed in a water body if fish were present (Bahls, 1990; Tyler et al., 1998a; Pilliod \& Peterson, 2001; Bull 
Table 6 Nonparametric multiplicative regression models predicting amphibian occupancy in fishless water bodies, based on water body habitat variables and whether fish were present in at least one water body in the surrounding catchment.

\begin{tabular}{|c|c|c|c|c|c|c|c|c|c|c|c|}
\hline Response & $\begin{array}{l}n \text { water } \\
\text { bodies }\end{array}$ & $\begin{array}{l}{ }^{*} n \text { variables in } \\
\text { final model }\end{array}$ & $\log \beta$ & $\dagger N^{*}$ & $\$$ Predictor 1 & Predictor 2 & $\$$ Tolerence & TSensitivity & Predictor 3 & Tolerence & Sensitivity \\
\hline $\begin{array}{l}\text { Salamander } \\
\text { occupancy }\end{array}$ & 966 & 3 & 16.4 & 74 & FISHSTATUS & ELEV & $131(10 \%)$ & 0.79 & DEPTH & $0.8(40 \%)$ & 0.13 \\
\hline Frog occupancy & 1410 & 3 & 42.1 & 91 & FISHSTATUS & VEG & $0.45(15 \%)$ & 0.38 & DEPTH & $0.3(15 \%)$ & 0.03 \\
\hline
\end{tabular}

ELEV, elevation of water body $(\mathrm{m})$; DEPTH, maximum water body depth $(<1,1-2,>2 \mathrm{~m})$; VEG, percentage of shoreline with emergent vegetation $(0-5 \%, 6-25 \%, 26-50 \%,>50 \%)$; FISHSTATUS, presence of non-native salmonids in at least one water body in catchment $(0,1)$.

${ }^{*}$ The number of predictors was determined by adding a variable if doing so increased $\log \beta$ by $\geq 10 \%$.

$\dagger N^{*}$ is the average neighbourhood size, or the average number of water bodies contributing to estimates at each point on the response surface. $\$$ FISHSTATUS is a categorical predictor; therefore, it has no tolerance or sensitivity estimates.

\$Lower tolerance values for predictors indicate a more restricted occupancy range relative to that predictor. The tolerance values are in same units as the original variable.

-High sensitivity values indicate greater importance of a predictor relative to other predictors in the model.

Figure 7 Nonparametric multiplicative regression modelled probability of Ambystoma macrodactylum occupancy in 966 fishless water bodies as a function of elevation. Separate probabilities are given for each combination of catchment fish status (FISHSTATUS or fish presence in a catchment) and maximum depth of the water body (DEPTH) resulting in six separate data series.

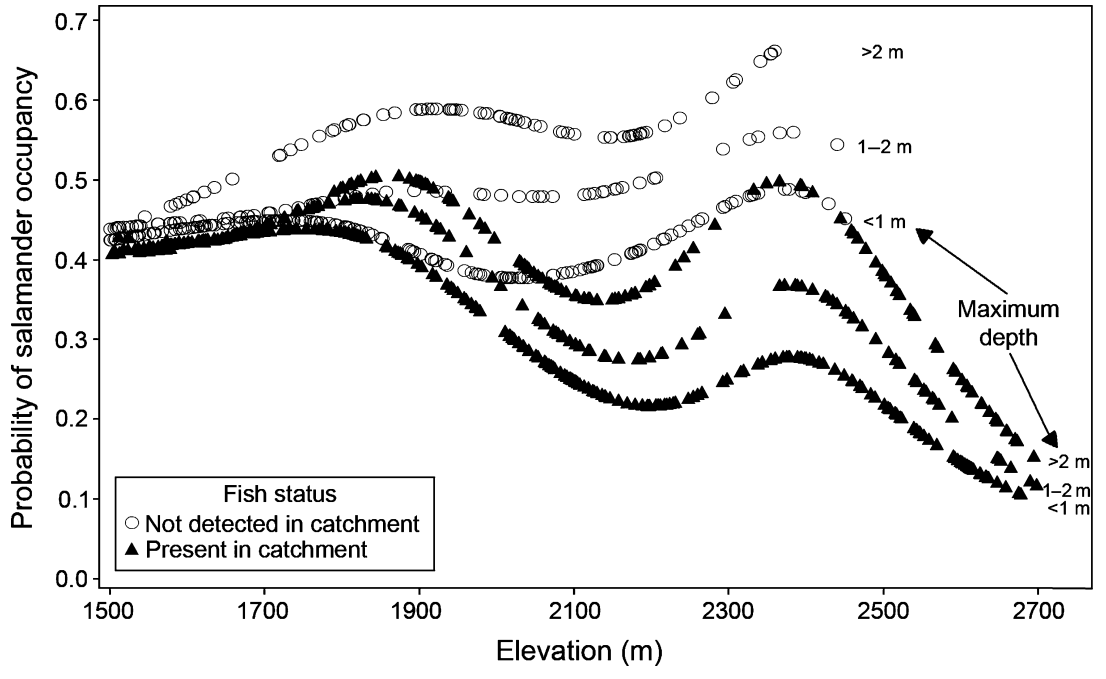

\& Marx, 2002; Welsh et al., 2006; Pearson \& Goater, 2008). The habitat requirements of fish and A. macrodactylum overlap at high elevations in the northern Rocky Mountains (Howard \& Wallace, 1985; Pilliod \& Peterson, 2001; Pearson \& Goater, 2008). In particular, fish and salamander larvae both require deeper water bodies $(>2 \mathrm{~m}$ ) at higher elevations to survive winter. We speculate that, over time, this niche overlap has resulted in extinction of $A$. macrodactylum in deeper water bodies as fish predominantly occupy water bodies $>2 \mathrm{~m}$ deep and are known predators of this species (Tyler et al., 1998b; Pearson \& Goater, 2009). The confounding effects of fish and water body depth made it difficult to understand the importance of depth for A. macrodactylum at the water body scale, but the NPMR analyses of fishless water bodies (see Fig. 7) clearly show that the probability of salamander occupancy is highest in the deepest water bodies when fish are absent. The few salamander populations that are able to persist with fish may rely on cover provided by thick emergent vegetation along shorelines and submerged boulders and cobble (D.S. Pilliod, P.F. Bahls, unpublished data, Tyler et al., 1998b; Pearson \& Goater, 2009) or fish populations might be small.

Decreased probability of A. macrodactylum occupancy in small catchments where at least one water body contained fish appeared to be influenced by some interaction of available habitat and habitat suitability of remaining fishless water bodies. Catchments with fewer water bodies had lower probability of occupancy, especially when fish were present in the catchment. As hypothesized (alternative hypothesis a), this could be the result of historically low salamander occupancy in catchments now occupied by fish. Given the widespread distribution of salamanders across the northern Rocky Mountains and the distribution of these particular catchments (i.e. not at the very edge of the species range), we found no evidence to support this hypothesis. Alternatively (b), this landscape-level effect of fish presence could result if fish effectively eliminated all potential habitats for salamanders within a catchment (i.e. a direct water body-level effect manifested as a catchment-level effect). This would occur if remaining fishless habitats in catchments with fish were 


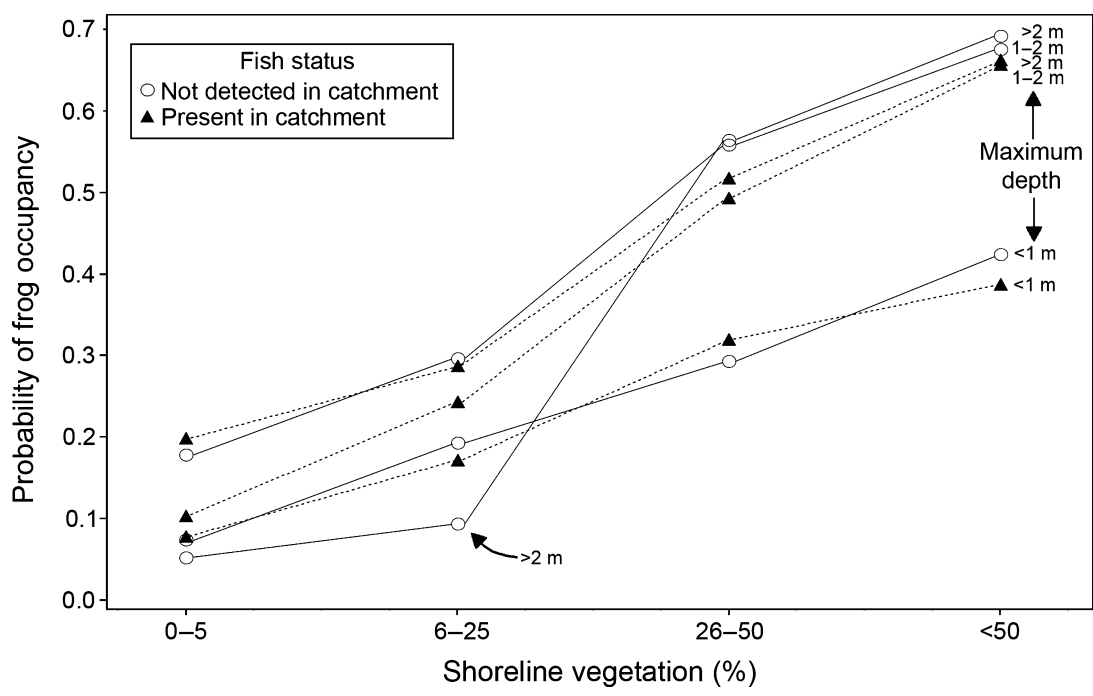

Figure 8 Nonparametric multiplicative regression modelled probability of Rana luteiventris occupancy in fishless water bodies as a function of shoreline vegetation (VEG). Separate probabilities are given for each combination of catchment fish status (FISHSTATUS or fish presence in a catchment) and maximum depth of the water body (DEPTH). Each of these six combinations is connected by lines for clarity. Solid lines indicate series where fish were not detected in catchments and dashed lines indicate series where fish were present in catchments. unsuitable for salamanders. Our analyses of A. macrodactylum occupancy in fishless water bodies in catchments with and without fish indicated that suitable fishless habitats were available in fish-occupied catchments and thus this hypothesis also was not supported.

We found the strongest support for the third alternative hypothesis (c) that many remaining fishless habitats are suitable for amphibians, but the presence of fish in a catchment somehow increases extinction risk for amphibians through various indirect processes. In our analyses of water bodies in fishless catchments, we found that A. macrodactylum was most likely to occupy deep water bodies ( $>2 \mathrm{~m}$ deep) at elevations ranging from 1900 to $2400 \mathrm{~m}$. One could consider this a reference condition, because fish had never occupied these catchments. However, when we examined the probability of A. macrodactylum occupancy across this 'preferred' range of habitat characteristics in fishless water bodies in catchments with fish, we found that the probability of occupancy was lower than in our fishless reference catchments. The cause of this decreased probability of occupancy is unknown, but may be the result of indirect factors (e.g. isolation, disrupted metapopulation dynamics). Because catchments occupied by fish offer less available habitat compared with fishless catchments, fish stocking may act as a form of both habitat loss and functional isolation for A. macrodactylum, increasing extinction risk at the catchment scale. This combination of population extirpation in water bodies with fish followed by the increased isolation of remaining populations in fishless water bodies has been suggested previously as a possible cause of documented disappearances of amphibians from fishless water bodies (Bradford et al., 1993; Knapp et al., 2003). Greater distances between extant populations decrease the likelihood of recolonization in the event of local extinction. This effect is diminished as the number of water bodies in a catchment increases, a pattern observed for A. macrodactylum in small catchments and the likely explanation for the lack of a negative effect of fish status on A. macrodactylum in large catchments. Even in California where extensive declines of yellow-legged frogs (Rana muscosa and Rana sierrae) are well documented, extinctions from large catchments are rare (Knapp \& Matthews, 2000; Knapp, 2005).

In contrast to A. macrodactylum, the presence of introduced salmonids had no negative effects on the occupancy of $R$. luteiventris at any spatial scale. Rana luteiventris are palatable to salmonids and fish can suppress the abundance of frog populations in water bodies where they co-occur (Pilliod \& Peterson, 2001), yet populations have high resistance to extinction and appear to coexist with fish (Bull \& Marx, 2002). The rapid development of $R$. luteiventris larvae allows the frogs to use a wide range of habitats, which we suspect limits their exposure to predatory fishes. Unlike A. macrodactylum, R. luteiventris was able to successfully breed in water bodies 1-2 m deep, habitats rarely stocked or inhabited by non-native fish. Where $R$. luteiventris and fish co-occur, tadpoles may be able to escape fish predation by using areas of the lake with shallow waters and complex habitat (e.g. dense emergent vegetation). The probability of frog occupancy greatly increased when $>25 \%$ of water body shoreline contained emergent vegetation, especially in water bodies $>1 \mathrm{~m}$ deep. We suspect this reflects a combination of breeding and overwintering habitat requirements for the species.

Differential effects of non-native fish on A. macrodactylum and $R$. luteiventris occupancy at different spatial scales may be explained by life history and population characteristics. Whereas both A. macrodactylum and R. luteiventris tend to have small effective population sizes (Funk et al., 1999, 2005b; Davis \& Verrell, 2005), R. luteiventris has higher fecundity than A. macrodactylum and may benefit from occasional 'boom' years of high recruitment. Further, the multi-year larval stage of A. macrodactylum at high elevations likely increases their exposure to predators. Ambystoma macrodactylum also has limited vagility (Tallmon et al., 2000) compared to R. luteiventris (Pilliod et al., 2002; Funk et al., 2005a,b), which may result in a higher extinction risk in catchments than 
R. luteiventris because declining local populations are less likely to be rescued by immigrants and recolonization rates are lower. Although overwintering habitats (i.e. deeper lakes, streams) of juvenile and adult $R$. luteiventris may be occupied by fish in some catchments (Pilliod \& Peterson, 2001), the high vagility of the species (Pilliod et al., 2002; Funk et al., 2005b) may spread risk and reduce the probability of catchment-wide extinction.

Extirpation of native amphibians from high-elevation catchments in the northern Rocky Mountains has important conservation implications. Populations of A. macrodactylum and $R$. luteiventris have low gene flow between high-elevation catchments, and recolonization is most likely to occur from lower elevation portions of drainages (Tallmon et al., 2000; Funk et al., 2005b; Giordano et al., 2007). Although possible, this process is slow and becoming less likely as lowelevation populations decline from loss of habitat in valley bottoms and decreased connectivity with mountain basins (Fisher \& Shaffer, 1996; Funk et al., 2005b). Climate change could further complicate this scenario as mountain snowpacks decline and hydrological patterns change (Cook et al., 2004).

Although A. macrodactylum is considered 'secure' by the International Union for Conservation of Nature (IUCN, 2009), our data suggest that non-native fish may increase risk of extinction of high-elevation populations at landscape scales in the northern Rocky Mountains and conservation measures may be warranted in some situations. The potential for successful management of non-native fishes in montane environments is a rare opportunity in national and international efforts to reverse or mitigate the effects of non-native species (Kats \& Ferrer, 2003). Amphibian populations can recover if fish die out following cessation of stocking (Funk \& Dunlap, 1999; Knapp et al., 2001, 2005; Eaton et al., 2005). Experiments in California have demonstrated that non-native fish can be successfully removed from water bodies $1-2$ ha in size, and native amphibian populations begin to recover within 1-2 years after fish elimination (Vredenburg, 2004; Knapp et al., 2007; Pope, 2008). Our findings suggest that fish removal or altered fish management practices (e.g. cessation of stocking) implemented as conservation measures for highelevation populations of A. macrodactylum in the northern Rocky Mountains may be most effective by targeting water bodies with the highest potential for salamander occupancy. Our analysis of salamander breeding habitat in fishless catchments suggests that water bodies targeted for fish removal should be $<2400 \mathrm{~m}$ elevation and have a maximum depth $>2 \mathrm{~m}$.

\section{ACKNOWLEDGEMENTS}

We thank the many funding agencies and field assistants for data used in this analysis. B.R.H. and the data collected in Glacier National Park were supported by the Department of the Interior Amphibian Research and Monitoring Initiative (ARMI). Patrick Murphy provided data for the Clearwater
National Forest. Robert Arkle assisted with NPMR analyses and Justin Welty assisted with figures. Christopher Pearl and Robert Klaver provided helpful comments on earlier versions of this manuscript. Sandra Poppenga and Alisa Gallant provided watershed delineation data from the US Geological Survey EROS Data Center. Brett Davis assisted with solar radiation modelling. Any use of trade, product or firm names is for descriptive purposes only and does not imply endorsement by the US Government.

\section{REFERENCES}

Adams, M.J., Schindler, D.E. \& Bury, R.B. (2001) Association of amphibians with attenuation of ultraviolet-b radiation in montane ponds. Oecologia, 123, 519-525.

Adams, M.J., Hossack, B.R., Knapp, R.A., Corn, P.S., Diamond, S.A., Trenham, P.C. \& Fagre, D.B. (2005) Distribution patterns of lentic-breeding amphibians in relation to ultraviolet radiation exposure in western North America. Ecosystems, 8, 488-500.

Anderson, J.D. (1967) A comparison of the life histories of coastal and montane populations of Ambystoma macrodactylum in California. American Midland Naturalist, 77, 323-354.

Bahls, P.F. (1990) Ecological implications of trout introductions to lakes of the Selway Bitterroot Wilderness, Idaho. Master's Thesis, Oregon State University, Corvallis, OR.

Bahls, P.F. (1992) The status of fish populations and management of high mountain lakes in the western United States. Northwest Science, 66, 183-193.

Bosch, J., Rincon, P.A., Boyero, L. \& Martínez -Solano, I. (2006) Effects of introduced salmonids on a montane population of Iberian frogs. Conservation Biology, 20, 180-189.

Bradford, D.F. (1989) Allotopic distribution of native frogs and introduced fishes in high Sierra Nevada lakes of California: implication of the negative effect of fish introductions. Copeia, 1989, 775-778.

Bradford, D.F., Tabatabai, F. \& Graber, D.M. (1993) Isolation of remaining populations of the native frog, Rana muscosa, by introduced fishes in Sequoia and Kings Canyon National Parks, California. Conservation Biology, 7, 882-888.

Braña, F., Frechila, L. \& Orizaola, G. (1996) Effect of introduced fish on amphibian assemblages in mountain lakes of northern Spain. Herpetological Journal, 6, 145-148.

Bull, E.L. \& Hayes, M.P. (2002) Overwintering of Columbia spotted frogs in northeastern Oregon. Northwest Science, 76, 141-147.

Bull, E.L. \& Marx, D.B. (2002) Influence of fish and habitat on amphibian communities in high elevation lakes in northeastern Oregon. Northwest Science, 76, 240-248.

Burnham, K.P. \& Anderson, D.R. (2002) Model selection and multimodel inference: a practical information-theoretic approach, 2nd edn. Springer, New York.

Cleveland, W.D. \& Devlin, S.J. (1988) Locally weighted regression: an approach to regression analysis by local 
fitting. Journal of the American Statistical Association, 83, 596-610.

Cook, E.R., Woodhouse, C.A., Eakin, C.M., Meko, D.M. \& Stahle, D.W. (2004) Long-term aridity changes in the western United States. Science, 302, 1015-1018.

Crump, M.L. \& Scott, N.J. Jr (1994) Visual encounter surveys. Measuring and monitoring biological diversity: standard methods for amphibians (ed. by W.R. Heyer, M.A. Donnelly, R.W. McDiarmid, L.C. Hayek and M.S. Foster), pp. 84-92, Smithsonian Institution Press, Washington, DC.

Davis, A.B. \& Verrell, P.A. (2005) Demography and reproductive ecology of the Columbia spotted frog (Rana luteiventris) across the Palouse. Canadian Journal of Zoology, 83, 702-711.

Eaton, B.R., Tonn, W.M., Paszkowski, C.A., Danylchuk, A.J. \& Boss, S.M. (2005) Indirect effects of fish winterkills on amphibian populations in boreal lakes. Canadian Journal of Zoology, 83, 1532-1539.

Fisher, R.N. \& Shaffer, H.B. (1996) The decline of amphibians in California's Great Central Valley. Conservation Biology, 10, 1387-1397.

Funk, W.C. \& Dunlap, W.W. (1999) Colonization of highelevation lakes by long-toed salamanders (Ambystoma macrodactylum). Canadian Journal of Zoology, 77, 1759-1767.

Funk, W.C., Tallmon, D.A. \& Allendorf, F.W. (1999) Small effective population size in the long-toed salamander. Molecular Ecology, 8, 1633-1640.

Funk, W.C., Greene, A.E., Corn, P.S. \& Allendorf, F.W. (2005a) High dispersal in a frog species suggests that it is vulnerable to habitat fragmentation. Biology Letters, 1, 13-16.

Funk, W.C., Blouin, M.S., Corn, P.S., Maxell, B.A., Pilliod, D.S., Amish, S. \& Allendorf, F.W. (2005b) Population structure of Columbia spotted frogs (Rana luteiventris) is strongly affected by the landscape. Molecular Ecology, 14, 483-496.

Gilpin, M.E. \& Soule, M.E. (1986) Minimum viable populations: processes of species extinctions. Conservation biology: the science of scarcity and diversity (ed. by M.E. Soule), pp. 19-34, Sinauer Associates, Sunderland, MA.

Giordano, A.R., Ridenhour, B.J. \& Storfer, A. (2007) The influence of altitude and topography on genetic structure in the long-toed salamander (Ambystoma macrodactylum). Molecular Ecology, 16, 1625-1637.

Hastie, T.J. \& Tibshirani, R.J. (1990) Generalized additive models. Chapman and Hall, London.

Hayes, M.P. \& Jennings, M.R. (1986) Decline of ranid frog species in western North America: are bullfrogs (Rana catesbeiana) responsible? Journal of Herpetology, 20, 490509.

Hobert, J.P., Altman, N.S. \& Schofield, C.L. (1997) Analyses of fish species richness with a spatial covariate. Journal of the American Statistical Association, 92, 846-854.

Hoffman, R.L., Larson, G.L. \& Samora, B. (2004) Responses of Ambystoma gracile to the removal of introduced nonnative fish from a mountain lake. Journal of Herpetology, 38, 578-585.
Hopey, M.E. \& Petranka, J.W. (1994) Restriction of wood frogs to fish-free habitats: how important is adult choice? Copeia, 1994, 1023-1025.

Hosmer, D.W. Jr \& Lemeshow, S. (1989) Applied logistic regression. John Wiley \& Sons, Inc, New York.

Howard, J.H. \& Wallace, R.L. (1985) Life history characteristics of populations of the long-toed salamander (Ambystoma macrodactylum) from different altitudes. American Midland Naturalist, 113, 361-373.

IUCN (International Union for Conservation of Nature). (2009) IUCN red list of threatened species. Version 2009.2. IUCN, Gland, Switzerland. Available at: http://www.iucnredlist.org (accessed 25 April 2010).

Kats, L.B. \& Ferrer, R.P. (2003) Alien predators and amphibian declines: review of two decades of science and the transition to conservation. Diversity and Distributions, 9, 99-110.

Kats, L.B. \& Sih, A. (1992) Oviposition site selection and avoidance of fish by streamside salamanders (Ambystoma barbouri). Copeia, 1992, 468-473.

Knapp, R.A. (2005) Effects of nonnative fish and habitat characteristics on lentic herpetofauna in Yosemite National Park, USA. Biological Conservation, 121, 265-279.

Knapp, R.A. \& Matthews, K.R. (2000) Nonnative fish introductions and the decline of the mountain yellow-legged frog from within protected areas. Conservation Biology, 14, 428-438.

Knapp, R.A., Matthews, K.R. \& Sarnelle, O. (2001) Resistance and resilience of alpine lake fauna to fish introductions. Ecological Monographs, 71, 401-421.

Knapp, R.A., Matthews, K.R., Preisler, H.K. \& Jellison, R. (2003) Developing probabilistic models to predict amphibian site occupancy in a patchy landscape. Ecological Applications, 13, 1069-1082.

Knapp, R.A., Hawkins, C.P., Ladau, J. \& McClory, J.G. (2005) Fauna of Yosemite National Park lakes has low resistance but high resilience to fish introductions. Ecological Applications, 15, 835-847.

Knapp, R.A., Boiano, D.M. \& Vredenburg, V.T. (2007) Removal of nonnative fish results in population expansion of a declining amphibian (mountain yellow-legged frog, Rana muscosa). Biological Conservation, 135, 11-20.

Kumar, L., Skidmore, A.K. \& Knowles, E. (1997) Modelling topographic variation in solar radiation in a GIS environment. International Journal of Geographic Information Science, 11, 475-497.

McCune, B. (2006) Nonparametric habitat models with automatic interactions. Journal of Vegetation Science, 17, 819-830.

McCune, B. (2009) Nonparametric multiplicative regression for habitat modeling. Available at: http://www.pcord.com/ NPMRintro.pdf (accessed 6 August 2010).

McCune, B. \& Mefford, M.J. (2009) HyperNiche. Multiplicative habitat modeling. Version 2.06. MjM Software, Gleneden Beach, OR, USA.

Munger, J.C., Gerber, M., Madrid, K., Carroll, M., Petersen, W. \& Heberger, L. (1998) U.S. National Wetland Inventory 
classifications as predictors of the occurrence of Columbia spotted frogs (Rana luteiventris) and Pacific treefrogs (Hyla regilla). Conservation Biology, 12, 320-330.

Murphy, P.D. (2002) The effects of different species of introduced salmonids on amphibians in headwater lakes of North-central Idaho. MS Thesis, Department of Biological Sciences, Idaho State University, Pocatello, ID.

Palen, W.J., Williamson, C.E., Clauser, A.A. \& Schindler, D.E. (2005) Impact of UV-B exposure on amphibian embryos: linking species physiology and oviposition behaviour. Proceedings of the Royal Society B, 272, 12271234.

Pearl, C.A., Adams, M.J. \& Wente, W.H. (2007) Characteristics of Columbia spotted frog (Rana luteiventris) oviposition sites in northeastern Oregon, USA. Western North American Naturalist, 67, 86-91.

Pearson, K.J. \& Goater, C.P. (2008) Distribution of long-toed salamanders and introduced trout in high- and low-elevation wetlands in southwestern Alberta, Canada. Ecoscience, 15, 453-459.

Pearson, K.J. \& Goater, C.P. (2009) Effects of predaceous and nonpredaceous introduced fish on the survival, growth, and antipredation behaviours of long-toed salamanders. Canadian Journal of Zoology, 87, 948-955.

Pilliod, D.S. \& Fronzuto, J.A. (2005) Ambystoma macrodactylum Baird, 1849: long-toed salamander. Amphibian declines: the conservation status of United States species (ed. by M.J. Lannoo), pp. 617-621, University of California Press, Berkeley, CA.

Pilliod, D.S. \& Peterson, C.R. (2001) Local and landscape effects of introduced trout on amphibians in historically fishless watersheds. Ecosystems, 4, 322-333.

Pilliod, D.S., Peterson, C.R. \& Ritson, P.I. (2002) Seasonal migration of Columbia spotted frogs (Rana luteiventris) among complementary resources in a high mountain basin. Canadian Journal of Zoology, 80, 1849-1862.

Pope, K.L. (2008) Assessing changes in amphibian population dynamics following experimental manipulations of introduced fish. Conservation Biology, 22, 1572-1581.

Pope, K.L., Garwood, J.M., Welsh., H.H. Jr \& Lawler, S.P. (2008) Evidence of indirect impacts of introduced trout on native amphibians via facilitation of a shared predator. Biological Conservation, 141, 1321-1331.

Poppenga, S.K. \& Worstell, B.B. (2008) Elevation-derived watershed basins and characteristics for major rivers of the conterminous United States. U.S. Geological Survey Scientific Investigations Report 2008-5153, Reston, Virginia.

Reaser, J.K. \& Pilliod, D.S. (2005) Rana luteiventris Thompson, 1913: Columbia spotted frog. Amphibian declines: the conservation status of United States species (ed. by M.J. Lannoo), pp. 559-563, University of California Press, Berkeley, CA.

Resetarits, W.J. \& Wilbur, H.M. (1989) Choice of oviposition site by Hyla Chrysoscelis: role of predators and competitors. Ecology, 70, 220-228.
Sjogren, P. (1991) Extinction and isolation gradients in metapopulations: the case of the pool frog (Rana lessonae). Biological Journal of the Linnean Society, 42, 135-147.

Smith-Gill, S.J. \& Berven, K.A. (1979) Predicting amphibian metamorphosis. American Naturalist, 113, 563-585.

Stebbins, R.C. (2003) A field guide to western reptiles and amphibians, 3rd edn. Houghton Mifflin Company, Boston.

Tallmon, D.T., Funk, W.C., Allendorf, F.W. \& Dunlap, W.W. (2000) Genetic differentiation of long-toed salamander (Ambystoma macrodactylum) populations. Copeia, 2000, 27-35.

Thoms, C., Corkran, C.C. \& Olson, D.H. (1997) Basic amphibian survey for inventory and monitoring in lentic habitats. Sampling amphibians in lentic habitats: methods and approaches for the Pacific Northwest (ed. by D.H. Olson, W.P. Leonard and R.B. Bury), pp. 35-46, Society for Northwestern Vertebrate Biology, Olympia, WA.

Tyler, T., Liss, W.J., Ganio, L.M., Larson, G.L., Hoffman, R., Deimling, E. \& Lomnicky, G. (1998a) Interaction between introduced trout and larval salamanders (Ambystoma macrodactylum) in high-elevation lakes. Conservation Biology, 12, 94-105.

Tyler, T.J., Liss, W.J., Hoffman, R.L. \& Ganio, L.M. (1998b) Experimental analysis of trout effects on survival, growth, and habitat use of two species of Ambystomatid salamanders. Journal of Herpetology, 32, 345-349.

Verdin, K.L. \& Verdin, J.P. (1999) A topological system for delineation and codification of the Earth's river basins. Journal of Hydrology, 218, 1-12.

Vredenburg, V.T. (2004) Reversing introduced species effects: experimental removal of introduced fish leads to rapid recovery of a declining frog. Proceedings of the National Academy of Sciences USA, 101, 7646-7650.

Welsh, H.H., Pope, K.L. \& Boiano, D. (2006) Subalpine amphibian distributions related to species palatability to nonnative salmonids in the Klamath Mountains of northern California. Diversity and Distributions, 12, 298-309.

\section{SUPPORTING INFORMATION}

Additional Supporting Information may be found in the online version of this article:

Figure S1 Estimated effect of habitat variables on probability of Ambystoma macrodactylum breeding occupancy in 114 large catchments in the northern Rocky Mountains.

Figure S2 Estimated effect of habitat variables on probability of Rana luteiventris breeding occupancy in 315 small catchments in the northern Rocky Mountains.

Figure S3 Estimated effect of habitat variables on probability of Rana luteiventris breeding occupancy in 149 large catchments in the northern Rocky Mountains. 
Table S1 Model results for long-toed salamander (Ambystoma macrodactylum) occupancy in 114 large catchments.

Table S2 Model results for Columbia spotted frog (Rana luteiventris) occupancy in 315 small catchments.

Table S3 Model results for Columbia spotted frog (Rana luteiventris) occupancy in 149 large catchments.

As a service to our authors and readers, this journal provides supporting information supplied by the authors. Such materials are peer-reviewed and may be re-organized for online delivery, but are not copy-edited or typeset. Technical support issues arising from supporting information (other than missing files) should be addressed to the authors.

\section{BIOSKETCH}

David Pilliod is a Research Ecologist with the US Geological Survey Forest and Rangeland Ecosystem Science Center in Boise, Idaho. His research focuses on wildlife-habitat relationships and the factors influencing wildlife population dynamics, community structure and species distributions. David is particularly interested in applications of long-term monitoring data.

Author contributions: D.S.P. conceived the ideas and led the writing; D.S.P. and B.R.H. analysed the data; D.S.P., B.R.H., B.A.M., P.F.B., E.L.B., P.S.C., G.H., J.C.M. and A.W. collected the data.

Editor: Anthony Ricciardi 